\title{
Neutraliteitsvraagstukken naar aanleiding van de leegloop van kerken
}

\author{
Jos Vleugel
}

\begin{abstract}
Of, en zo ja, in welke specifieke gevallen is het beginsel van de scheiding tussen kerk en staat van toepassing op situaties die verband houden met de leegloop van kerken? Overheden kunnen naar aanleiding van de sluiting, restauratie en de her-en nevenbestemming van kerkgebouwen geconfronteerd worden met kwesties die raken aan dit beginsel. Op basis van een contextuele benadering wordt in deze bijdrage duidelijk gemaakt welke belangen (het religieuze, het algemene, het particuliere en het belang van anderen) er binnen de verschillende domeinen doorslaggevend zouden moeten zijn bij het beleid van overheden op dit gebied.
\end{abstract}

\section{Inleiding}

Ten gevolge van secularisatie en ontkerkelijking zijn er de afgelopen decennia veel kerken aan de eredienst onttrokken. Sinds 2008 zouden dat er naar schatting ongeveer elke week twee zijn. ${ }^{1}$ Het gevolg is dat kerken worden afgebroken, komen leeg te staan of een nieuwe bestemming krijgen. Veel gemeenten en kerkeigenaren worstelen met kerkgebouwen die leegstaan of die een onzekere toekomst tegemoet gaan. Naar aanleiding daarvan heeft het ministerie van Onderwijs, Cultuur en Wetenschap in 2018 een samenwerkingsprogramma opgezet getiteld 'De Nationale Kerkenaanpak'. De bedoeling is dat provincies, gemeenten, kerkeigenaren en erfgoedorganisaties samenwerken aan een toekomstbestendige invulling van kerkgebouwen. Volgens de Rijksdienst Cultureel Erfgoed (RCE) zijn inmiddels honderd gemeenten aan de slag gegaan met het opstellen van een zogeheten 'Kerkenvisie'. ${ }^{2}$ Hierin wordt aangegeven welke toekomst de genoemde partijen zien voor 'hun' kerkgebouwen: kerkelijk gebruik, nevengebruik, sluiting, herbestemming, verkoop of bijvoorbeeld sloop. Het gezamenlijk komen tot een visie vraagt om een nauwe samenwerking, die voor de betrokken partijen lang niet altijd even eenvoudig blijkt te zijn. ${ }^{3}$ Een complicerende factor in deze samenwerking is dat de verhouding tussen religieuze organisaties en de overheid juridisch ingekaderd wordt door het beginsel van scheiding tussen kerk en staat.

Deze bijdrage richt zich op de rol van de overheid inzake de leegloop van kerken vanuit het beginsel van de scheiding tussen kerk en staat. Eerst wordt ingegaan op de vraag in hoeverre dit beginsel op onderhavige thematiek van toepassing is (paragraaf 2). Het kan namelijk slechts aan de orde zijn als er godsdienst of religie

1 Zie de bijdrage van Honingh en Nelissen, 'De strijd om kerken', in dit themanummer.

2 Cultureelerfgoed.nl. Zoek op: nationale kerkenaanpak. Geraadpleegd juni 2020.

3 Zie de bijdrage van Honingh en Nelissen, 'De strijd om kerken', in dit themanummer. 
in het spel is. Hoe zit dat bij de subsidiëring van kerkgebouwen met het oog op restauratie, verbouwing of herbestemming? Is die gericht op de religieuze functie van kerkgebouwen of blijft dit aspect buiten beschouwing en daarmee ook de scheiding tussen kerk en staat? als het beginsel van scheiding tussen kerk en staat van toepassing kan worden geacht, kan de vervolgvraag worden gesteld wat dit dan voor consequenties heeft. Met andere woorden, welke benadering inzake de leegloop van kerken schrijft het beginsel van de scheiding tussen kerk en staat de overheid voor? Om deze vraag te kunnen beantwoorden wordt dit beginsel aan de hand van het geldende recht nader geduid (paragraaf 3 ). Hieruit volgt dat de betekenis van het beginsel van de scheiding tussen kerk en staat afhankelijk is van vier te onderscheiden contexten (paragraaf 4). Met deze context-benadering zal vervolgens worden nagegaan welke rol de overheid zou moeten hebben ten aanzien van de leegloop van kerken (paragraaf 5). Is de gemeente bijvoorbeeld bevoegd om er bij kerkgemeenschappen op aan te dringen dat verschillende religieuze denominaties samen een kerkgebouw delen of dat een kerkgebouw wordt herbestemd als kerkgebouw voor een migranten-kerkgemeenschap of als moskee? Ook kunnen vanuit de context-benadering vragen worden beantwoord over de subsidiëring van een kerkgebouw vanwege de religieuze functie ervan. Is dit toegestaan, en zo ja, onder welke voorwaarden? Een vraag in het verlengde hiervan is of financiële steun voor het behoud van een kerkgebouw ook betekent dat een overheid een tegenprestatie van de kerkgemeenschap mag verlangen. Mag een overheid verlangen dat een kerkgebouw ook een andere functie krijgt, die het algemeen belang dient, zoals een buurthuis of een kiesbureau? Deze bijdrage wordt afgesloten met een conclusie (paragraaf 6).

\section{Wanneer is de scheiding tussen kerk en staat aan de orde?}

De behandeling van kerkelijke of religieuze gemeenschappen wordt vanuit het recht gekleurd door het beginsel van de scheiding tussen kerk en staat. Dit beginsel is niet in de Nederlandse Grondwet of in internationale verdragen vastgelegd. Het beginsel vloeit in belangrijke mate voort uit de godsdienstvrijheid en het discriminatieverbod, die wel in de Grondwet en internationale verdragen zijn opgenomen. De kern van het beginsel van scheiding tussen kerk en staat (zie VNG \& BZK, 2020: 6) is dat de overheid geen godsdienst of godsdienstige praxis mag voorschrijven of bevoordelen en dat de overheid zich niet mag bemoeien met de inhoud van een godsdienst. ${ }^{4}$ De overheid moet zich dus neutraal opstellen. De vraag wat het nu in verschillende contexten betekent dat de overheid zich neutraal moet opstellen, behandelen we in paragraaf 3 . Eerst dienen we stil te gestaan bij de vraag wanneer het beginsel van scheiding tussen kerk en staat überhaupt aan de orde is. Daarvoor moet worden beoordeeld of de bovengenoemde grondrechten van toepassing zijn. De godsdienstvrijheid is onder andere

4 Dit laatste onderdeel wordt wel geduid als het leerstuk van interpretatieve terughoudendheid. Het staat de rechter of andere overheidsorganen niet vrij om over dogmatische en theologische leerstellingen te oordelen. HR 15 februari, NJ 1957, 201. Zie hierover Vleugel, 2018: 67. 
neergelegd in artikel 9 van het EVRM en artikel 6 van de Grondwet. ${ }^{5}$ Het verbod om te discrimineren naar godsdienst is onder andere neergelegd in artikel 1 van de Grondwet. ${ }^{6}$ De formuleringen van bovengenoemde bepalingen hebben met elkaar gemeen dat de term godsdienst erin voorkomt. Voor een beoordeling of deze grondrechten (en daarmee het beginsel van de scheiding tussen kerk en staat) van toepassing kunnen zijn, dient daarom ten eerste te worden bepaald of er sprake is van godsdienst.

Over de inhoudelijke betekenis van het fenomeen godsdienst is op grond van de grondwetsgeschiedenis en de geschiedenis van het EVRM maar weinig te zeggen. ${ }^{7}$ Dit komt ook door de scheiding tussen kerk en staat. De wetgever en de verdragspartijen hebben zich niet te veel willen uitspreken over wat godsdienst in juridische zin is. Anders zouden zij zich als een soort supertheoloog opstellen en daarmee hun neutraliteit verliezen. Buiten kijf staat echter dat de overtuigingen van de traditionele religieuze stromingen en hun praxis als zodanig worden erkend (Murdoch, 2012: 12). Dit is voor deze bijdrage relevant want de leegloop van religieuze gebouwen heeft nagenoeg uitsluitend betrekking op die godsdiensten. Uiteraard geldt wel dat er pas gesproken kan worden van een gebouw met een religieuze functie als dat gebouw voor godsdienstoefening gebruikt wordt. Kortom, zo gauw in het contact dat een overheid heeft met een religieuze organisatie godsdienst (of levensbeschouwing) een rol speelt, dan is het beginsel van scheiding tussen kerk en staat aan de orde, in de zin dat de overheid de godsdienstvrijheid en het gelijkheidsbeginsel in acht dient te nemen.

Het beginsel van de scheiding tussen kerk en staat lijkt daarom ook niet van toepassing te zijn als het gaat om de financiering van kerkgebouwen met een monumentenstatus. Kerkeigenaren kunnen op grond van artikel 7.3 Erfgoedwet in aanmerking komen voor een subsidie of een lening in het kader van behoud,

5 Artikel 9 van het EVRM luidt: '1. Een ieder heeft recht op vrijheid van gedachte, geweten en godsdienst; dit recht omvat tevens de vrijheid om van godsdienst of overtuiging te veranderen, alsmede de vrijheid hetzij alleen, hetzij met anderen, zowel in het openbaar als privé zijn godsdienst te belijden of overtuiging tot uitdrukking te brengen in erediensten, in onderricht, in praktische toepassing ervan en in het onderhouden van geboden en voorschriften; 2 . De vrijheid zijn godsdienst te belijden of overtuiging tot uiting te brengen kan aan geen andere beperkingen worden onderworpen dan die welke bij de wet zijn voorzien en in een democratische samenleving noodzakelijk zijn in het belang van de openbare veiligheid, voor de bescherming van de openbare orde, gezondheid of goede zeden of voor de bescherming van de rechten en vrijheden van anderen.' Artikel 6 van de Grondwet luidt: 1. Ieder heeft het recht zijn godsdienst of levensovertuiging, individueel of in gemeenschap met anderen, vrij te belijden, behoudens ieders verantwoordelijkheid volgens de wet; 2 . De wet kan ter zake van de uitoefening van dit recht buiten gebouwen en besloten plaatsen regels stellen ter bescherming van de gezondheid, in het belang van het verkeer en ter bestrijding of voorkoming van wanordelijkheden.'

6 Artikel 1 van de Grondwet luidt: 'Allen die zich in Nederland bevinden, worden in gelijke gevallen gelijk behandeld. Discriminatie wegens godsdienst, levensovertuiging, politieke gezindheid, ras, geslacht of op welke grond dan ook, is niet toegestaan.'

7 Zie Kamerstukken II 1975/76, 13 872, nr. 3 en Van Boven, 1967: 124. Overigens erkennen de wetgever en de verdragspartijen wel dat de godsdienstoefening zich op bepaalde algemene wijzen manifesteert. Genoemd worden de eredienst, het onderricht, het praktiseren en onderhouden van een godsdienst. 
restauratie of herbestemming van hun kerkgebouw. In lagere regelgeving (Subsidieregeling instandhouding monumenten (Sim)) is bepaald dat kerkeigenaren voor een periode van zes jaar in aanmerking komen voor een instandhoudingssubsidie van $60 \%$ van de gemaakte kosten voor het 'normale onderhoud' van het kerkmonument (art. 2.1 van de regeling). Een kerk wordt echter niet gefinancierd vanwege zijn religieuze functie, maar vanwege bepaalde algemene belangen. Welke dat zijn, staat in artikel 3 van de Erfgoedwet: schoonheid, betekenis voor de wetenschap of cultuurhistorische waarde. Dat in de beschrijving van het begrip 'kerkelijk monument' in de Erfgoedwet sterk wordt gerefereerd aan de religieuze functie van een kerk, maakt dit niet anders. ${ }^{8}$ Voor het behoud, restauratie of de herbestemming van kerkelijke monumenten worden ook wel op decentraal niveau subsidies verstrekt door de besturen van provincies of gemeenten. Ook daar gaat het in veel gevallen om bekostiging op grond van de eerdergenoemde 'neutrale' gronden en niet om subsidie vanwege de religieuze functie van een gebouw. Ook dan blijft het beginsel van de scheiding tussen kerk en staat buiten beeld (Van Sasse van Ysselt, 2013: 70). Wanneer is in het kader van het beleid inzake de leegloop van kerken het beginsel van de scheiding tussen kerk en staat dan wel aan de orde? Voordat we hier verder op ingaan in paragraaf 3 , behandelen we eerst de betekenis van het beginsel van scheiding tussen kerk en staat.

\section{Wat behelst de scheiding tussen kerk en staat?}

Het Europees Hof voor de Rechten van de Mens (EHRM) heeft de rol van de verdragsstaten ten opzichte van religie meermaals gekenmerkt als die van een 'neutral and impartial organiser of religions'. ${ }^{9}$ Op welke manier de verdragsstaten van het EVRM concreet invulling geven aan deze beschrijving, is afhankelijk van de unieke traditionele kerk en staat-verhoudingen in de verschillende Europese landen. Dat is ook de reden (zie Post \& Van der Schyff, 2014) dat het EHRM bij de beoordeling van claims op de godsdienstvrijheid uitgaat van een margin of appreciation. In Frankrijk wordt bijvoorbeeld op een andere wijze invulling gegeven aan een neutrale overheid dan in Nederland. ${ }^{10}$

De wijze waarop de Nederlandse staat invulling geeft aan zijn neutrale rol, kan worden afgeleid uit de wetsgeschiedenis, de systematiek van het geldende recht en de jurisprudentie. In eerder werk heb ik dit uitgebreid beschreven en gedocumenteerd Vleugel, 2019, 2020). Daarom beperk ik mij er in deze bijdrage toe om enkel de hoofdlijnen hiervan te schetsen. Binnen de Nederlandse rechtsorde

8 Artikel 1.1 sub c Erfgoedwet: 'monument dat eigendom is van een kerkgenootschap, een zelfstandig onderdeel daarvan, een lichaam waarin kerkgenootschappen zijn verenigd, of van een ander genootschap op geestelijke grondslag en dat uitsluitend of voor een overwegend deel wordt gebruikt voor het gezamenlijk belijden van de godsdienst of levensovertuiging'.

9 EHRM 13 februari 2003 (GK), nr. 41340/98, 41342/98, 41343/98 en 41344/98, NJ 2005, 73, m.nt. Alkema, $A B$ 2003, 152, m.nt. Kanne, ECLI:NL:XX:2003:AN7452 (Refah Partisi (the Welfare Party) e.a.v Turkije), par. 119.

10 In Frankrijk is de laïcité de norm: voor religieuze uitingen en gedragingen is in het publieke domein geen plaats. 
kunnen vier 'contexten' of domeinen worden onderscheiden, die elk gekenmerkt worden door een eigen verhouding met neutraliteit: (1) het intern religieuze domein, (2) het openbare domein, (3) het overheidsdomein en (4) het domein van particuliere instellingen. De wijze waarop een domein zich verhoudt met neutraliteit, is van groot belang voor de werking van de godsdienstvrijheid en het gelijkheidsbeginsel en daarmee voor de concretisering van het beginsel van de scheiding tussen kerk en staat. De verhouding van een domein met neutraliteit bepaalt namelijk de wettelijk uit te voeren belangenafweging in het kader van de godsdienstvrijheid, eventueel ingeroepen in samenhang met het gelijkheidsbeginsel. Een dergelijke belangenafweging volgt direct uit artikel 9 EVRM. Een bevoegd overheidsorgaan dat beperkingen wil opleggen aan de godsdienstvrijheid of in het kader van de positieve verplichtingen van grondrechten maatregelen moet nemen of faciliteiten moet verlenen, dient naast de overige eisen van artikel 9 lid 2 EVRM (zoals een proportionaliteits- en subsidiariteitstoets) ook een afweging te maken tussen het religieuze belang van het grondrechtssubject en een in de beperkingsclausule genoemd algemeen belang of belang van een ander. Afhankelijk van de wijze waarop een domein zich met neutraliteit verhoudt, zal er meer of minder waarde worden gehecht aan het religieuze belang van een rechtssubject of aan het algemeen belang of belang van een ander.

\section{De verhouding van verschillende maatschappelijke domeinen met neutraliteit}

De genoemde domeinen kennen een fysieke component - een concrete plaats of ruimte - die correspondeert met een denkbeeldige component - een abstracte vrijheidssfeer.

Ten eerste is er het intern religieuze domein. In fysieke zin kan dan gedacht worden aan de eigen woning, het kerkgebouw of de (bijzondere) school met religieuze signatuur. Die fysieke plaatsen corresponderen dan respectievelijk met de huiselijke sfeer, de kerkgemeenschap en de schoolgemeenschap. ${ }^{11}$ In het intern religieuze domein geldt in belangrijke mate het tegenovergestelde van neutraliteit. Het is juist geaccepteerd dat in dit domein een omvattend begrip van het 'goede leven' wordt beleden. Een ouder mag zijn kind religieus opvoeden, bijzondere (religieuze) scholen mogen godsdienstig gekleurd onderwijs aanbieden en kerkgenootschappen hebben 'inrichtingsvrijheid' onder andere voor wat betreft de wijze waarop zij in woord en daad aan hun godsdienst uiting geven. De overheid houdt zich in dit domein zoveel mogelijk afzijdig. Wanneer burgers worden belemmerd in het uitoefenen van hun rechten in dit verband, kan er voor de overheid een positieve verplichting gelden om dit alsnog mogelijk te maken. ${ }^{12}$ Het religieuze belang gaat in dit domein in het geval van een belangenafweging in beginsel voor op het algemeen belang. Het intern religieuze domein is voor het onderwerp van deze bijdrage relevant, aangezien hieronder ook de invulling van de eredienst en 
de daarmee verbonden inrichting en architectuur van het kerkgebouw kan worden begrepen.

Ten tweede is er het openbare domein. Dit domein omvat in fysieke zin de openbare ruimte, openbare overheidsgebouwen, openbaar vervoer en openbaar onderwijs. In abstracte zin is dit het domein waar men in beginsel niet is gebonden aan de eerdergenoemde verbanden van het intern religieuze domein, en aan de hierna te noemen verbanden van het domein van particuliere instellingen en het overheidsdomein. ${ }^{13}$ Volgens de grondwetgever is binnen het openbare domein net als in het privédomein (intern religieuze domein) eenieder in beginsel vrij om zich religieus te kunnen uiten (art. 6 lid 2 Grondwet). ${ }^{14}$ Doordat eenieder op gelijke wijze van de godsdienstvrijheid mag genieten, is de consequentie dat het openbare domein een religieus pluriform karakter draagt. De overheid heeft als taak ervoor te zorgen dat er in het publieke domein ruimte is voor religieuze pluriformiteit. De neutraliteit die heerst binnen het openbare domein, wordt wel als een inclusief begrip van neutraliteit gekenschetst (Van der Burg, 2009: 35 e.v.). Neutraliteit is dan een zichtbare pluriformiteit waardoor iedereen in zijn andersheid gelijk is. Ook in dit domein heeft bij een belangenafweging door de overheid het religieuze belang een zwaarwegend gewicht, maar in tegenstelling tot het intern religieuze domein doen in dit domein het algemeen belang en het belang van anderen niet per definitie onder voor dit belang. Voor het onderwerp van deze bijdrage lijkt het openbare domein niet echt aan de orde te zijn, aangezien het daarbij vooral lijkt te gaan om de godsdienstoefening binnen een kerkgebouw en niet de openbare godsdienstoefening. De thematiek van de leegloop van kerken lijkt zich hiertoe niet uit te strekken.

Ten derde kan het overheidsdomein worden onderscheiden. In fysieke zin heeft dit domein betrekking op besloten overheidsgebouwen, in denkbeeldige zin gaat het dan om de arbeidsverhoudingen binnen de overheid en om de professionele houding van de overheid richting burgers die diensten van deze overheid afnemen. ${ }^{15}$ Binnen dit domein is in beginsel ook sprake van een inclusieve vorm van neutraliteit. Als het echter gaat om de positie van ambtenaren die in contact treden met burgers, is hier traditioneel minder ruimte voor. Grondrechten van ambtenaren, zoals de godsdienstvrijheid, mogen eerder worden beperkt dan die van burgers. ${ }^{16}$ Als het aankomt op het belang van onpartijdigheid van de overheid, kan daarom worden gesteld dat soms zelfs een meer seculiere benadering van neutraliteit wordt gevolgd. Met andere woorden, bij een belangenafweging in dit domein prevaleert in veel gevallen het algemeen belang boven dat van ambtsdragers of ambtenaren. Van een rechter mag bijvoorbeeld worden geëist dat hij geen islamitische hoofddoek draagt. Voor dit domein geldt dat het voor het onderwerp van deze bij- 
drage enkel relevant is voor zover het gaat om de wijze waarop ambtenaren of ambtsdragers in contact treden met kerkbesturen.

Tot slot is er het domein van particuliere instellingen. Hierbij kan als voorbeeld een bedrijfsruimte worden genoemd. Qua abstracte vrijheidssfeer correspondeert deze plaats met de arbeidsverhouding tussen werkgever en werknemer, die van een instelling met haar cliënt en die tussen instellingen onderling. ${ }^{17}$ Onder dit domein valt ook de civielrechtelijke verhouding tussen particuliere instellingen en als de overheid als civielrechtelijke rechtspersoon optreedt ook de verhouding tussen de overheid en particuliere instellingen. Dit domein wordt in beginsel net als het publieke domein gekenmerkt door een inclusieve neutraliteit. Op de werkvloer hoeven werknemers bijvoorbeeld hun religieuze identiteit niet te verbergen en er ook geen nadeel van te ondervinden. ${ }^{18}$ Van deze inclusief neutrale benadering en daarmee van de plicht tot het accommoderen van religieuze pluriformiteit kan echter worden afgeweken wanneer partijen, zonder daarbij in een afhankelijkheidsverhouding te zitten, contractueel vastleggen dat zij afstand doen van hun grondrechten. ${ }^{19}$ Dit vloeit voor uit het aan het civielrecht ten grondslag liggende rechtsbeginsel van contractsvrijheid. Bij een belangenafweging in het kader van dit domein kan vanwege de contractsvrijheid het particuliere belang (het belang van een ander ${ }^{20}$ ) boven het religieuze belang worden gesteld. Voor het onderwerp van deze bijdrage is dat relevant, aangezien dit betekent dat de overheid met kerkeigenaren overeenkomsten kan sluiten waarin expliciet of impliciet door kerkeigenaren afstand wordt gedaan van rechten die kunnen worden gezien als onderdeel of uitvloeisel van de godsdienstvrijheid.

\section{Neutraal overheidsbeleid inzake de leegloop van kerken}

\subsection{Beleid inzake de leegloop van kerken binnen de context van het intern religieuze domein}

\section{- Terughoudende overheid}

Zoals gesteld dient de overheid binnen het intern religieuze domein qua inhoud en vorm van de geloofsmanifestatie een zo groot mogelijke terughoudendheid te betrachten. Ook het gebruik van een kerkgebouw valt binnen het intern religieuze domein. Het kerkgebouw is immers primair bedoeld als object waarbinnen de eredienst tot uitdrukking komt. In de jurisprudentie wordt de eredienst als volgt omschreven: '(...) een in beginsel voor een ieder toegankelijke bijeenkomst tot gezamenlijke verering van een opperwezen, waarbij zekere vormvoorschriften (liturgie, orde van dienst, ritueel) in acht genomen worden'. ${ }^{21}$ De eredienst is een

17 Artikel 9 EVRM jo. artikel $6 \mathrm{Gw}$.

18 Kantonrechter Tiel 1 september 2004, ECLI:NL:RBARN:2004:AS6299.

19 Zie voor een jurisprudentieoverzicht van zaken waarbij grondrechten op privaatrechtelijke wijze zijn beperkt: Kortmann, 2016: 370.

20 In artikel 9 lid 2 EVRM wordt naast het algemeen belang (in het kader van rechten en vrijheden) het belang van anderen onderscheiden. Zie noot 6 .

21 HR 7 mei 1980, BNB 1980/177. 
vorm van godsdienstig belijden die op grond van de Grondwet (art 6 lid 1) en het EVRM (art. 9 lid 1) de hoogste mate van bescherming geniet. ${ }^{22}$

Gezien het religieuze doel van een kerkgebouw past het de overheid niet wanneer zij druk op een kerkbestuur uitoefent om een kerkgebouw te herbestemmen, te nevenbestemmen, te restaureren of te verbouwen. ${ }^{23}$ Het staat een kerkbestuur vrij om in een oud, vervallen kerkgebouw (mits is voldaan aan de brand- en veiligheidsvoorschriften) samen te komen. Een overheid (centraal of decentraal) kan niet van een kerkbestuur eisen dat er kosten worden gemaakt omdat een kerk volgens overheidsstandaarden religieus erfgoed is. Het belang van de religieuze autonomie van een kerkgemeenschap dient hier in beginsel te prevaleren boven het algemeen belang dat waarde hecht aan het behoud van cultureel erfgoed. Hetzelfde geldt voor het herbestemmen van kerkgebouwen. Het kerkbestuur is vrij om te beslissen wat er met het gebouw dient te gebeuren als de kerkgemeente niet meer levensvatbaar is. Zij hoeven er niet mee in te stemmen wanneer er van overheidswege een plan wordt bedacht waarbij hun kerkgebouw een bestemming krijgt waarvan zij vinden dat die niet past bij hun godsdienstige overtuigingen (bijvoorbeeld als moskee ${ }^{24}$ ). Ook moet een overheid voorzichtig zijn met het opperen van het idee dat een geloofsgemeenschap haar kerk wel zou kunnen delen met andere geloofsgemeenschappen. Het is goed voor te stellen dat hiertegen theologische (of religieuze) bezwaren bestaan. Dit geldt eveneens voor het idee dat kerkgebouwen doordeweeks een nevenfunctie zouden kunnen krijgen, zoals dorpshuis of stembureau. Het bepalen van de functie van een kerkgebouw betreft een religieuze aangelegenheid waarmee de overheid zich eigenlijk niet dient te bemoeien. Vanuit dit perspectief gaat een overheid dan ook een grens over wanneer zij bij de subsidiëring van een kerkgebouw voorwaarden stelt die raken aan de religieuze functie van het kerkgebouw. Of die subsidie verstrekt wordt vanwege het algemeen belang (behoud cultureel erfgoed) of vanwege de religieuze functie, doet daarbij niet ter zake.

\section{- Overheidssubsidie voor de religieuze functie van een kerkgebouw?}

Normaal gesproken past de subsidiëring van religieuze activiteiten van een kerkgemeenschap door de (gemeentelijke) overheid niet bij de wijze waarop het intern-religieuze domein zich verhoudt met neutraliteit. ${ }^{25}$ Gesteld kan worden dat er dan geen sprake is van een terughoudende opstelling. De overheid laat immers met een dergelijk subsidiëring blijken een voorkeur te hebben voor godsdienst in het algemeen of een godsdienst in het bijzonder. Ook financiering van

22 Eredienst wordt expliciet als onderdeel van de godsdienstvrijheid genoemd in artikel 9 EVRM.

23 Zie anders VNG \& BZK, 2020: 30. De opstellers hiervan menen dat de gemeente kan besluiten 'de regie' te nemen' bij herbestemming. Dit lijkt me alleen geoorloofd wanneer deze regie een volstrekt vrijblijvend karakter heeft. Ook stellen de opstellers dat het van belang is dat partijen naar elkaar toe bewegen. Ook hierbij geldt dat kerkbesturen in hun recht staan als zij niet meebewegen.

24 Daartegen bestaan vooral binnen de katholieke kerk grote bezwaren. Zie: 'De kerk die een moskee werd: dat gebeurt nu niet meer', Trouw 2 juli 2019.

25 Zie VNG \& BZK, 2020 en zie ook Aanhangsel Handelingen II 2009/10, 1032 (vragen over gemeentelijk subsidiebeleid van Amsterdam inzake identiteitsgebonden organisaties). 
religieuze gebouwen door buitenlandse overheden is om die reden problematisch (Van Sasse van Ysselt, 2013: 72). Er kan dan wel worden betoogd dat de steun niet afkomstig is van de eigen overheid, maar feit blijft dat bepaalde religieuze gemeenschappen wel overheidssteun krijgen en andere niet. Verder is in dit verband ook de vrijstelling van kerkgebouwen van onroerendezaakbelasting omstreden. 'Onroerende zaken die in hoofdzaak zijn bestemd voor de openbare eredienst of voor het houden van openbare bezinningssamenkomsten van levensbeschouwelijke aard, met uitzondering van delen ervan die dienen als woning', zijn vrijgesteld van onroerendezaakbelasting. ${ }^{26}$

Dit belastingvoordeel voor religieuze of levensbeschouwelijke organisaties is direct van aard en wordt dus gegeven vanwege de religieuze functie van het gebouw en niet omdat ze bijdragen aan het algemeen belang. De vraag is of de wetgever deze wettelijke constructie niet beter kan aanpassen zodat het belastingvoordeel niet gegeven wordt vanwege de religieuze functie zelf maar bijvoorbeeld vanwege het algemene belang dat religie in de maatschappij vervult. Een dergelijke constructie vinden we ook ten aanzien van de ANBI-regeling. Daar wordt godsdienst naast cultuur et cetera neergezet als algemeen belang (art. 5b lid 3 Algemene Wet inzake Rijksbelastingen (AWR) $)^{27}$ met als gevolg dat er een milder belastingregime geldt voor kerkelijke instellingen.

Er zijn gevallen denkbaar waarbij financiële ondersteuning van een religieuze gemeenschap ten behoeve van de religieuze functie van een kerkgebouw wel rechtmatig kan worden geacht. Vanuit de positieve verplichtingen die de grondrechten (waaronder de godsdienstvrijheid) met zich brengen, kan worden beargumenteerd dat de overheid in sommige gevallen een verplichting heeft om financiële steun te bieden. Dit kan bijvoorbeeld het geval zijn als een religieuze gemeenschap niet een plaats heeft om een eredienst te kunnen houden of wanneer de plaats die zij hebben wegens verval of hoge onderhoudskosten niet meer te gebruiken is of niet meer voldoet aan de veiligheids- of brandweervoorschriften. In die gevallen is het alleszins redelijk als een (decentrale) overheid op grond van de positieve verplichtingen van de godsdienstvrijheid een 'steentje' bijdraagt. Er zal dan niet snel sprake zijn van ongelijke behandeling aangezien een dergelijke subsidie wordt verleend vanwege de bijzondere omstandigheden van het concrete geval. Ook kan niet gesteld worden dat er dan in strijd met het beginsel van de scheiding tussen kerk en staat wordt gehandeld, aangezien de subsidie verstrekt wordt om een religieuze gemeenschap de gelegenheid te bieden gebruik te kunnen maken van haar grondrecht, namelijk het beoefenen van de

26 De grondslag voor dit belastingvoordeel is te vinden in artikel 2 sub g Uitvoeringsregeling uitgezonderde objecten Wet waardering onroerende zaken en artikel 220d sub c Gemeentewet.

27 Overigens blijkt niet uit de wetsgeschiedenis van deze bepaling waarom religie van algemeen nut zou zijn. Verwezen wordt naar de wijze waarop het begrip algemeen nut zich heeft uitgekristalliseerd in de jurisprudentie. Kamerstukken II 2011/12, 33 006, nr. 3, p 25. 
eredienst. Zonder de mogelijkheid tot het houden van een eredienst heeft de godsdienstvrijheid immers geen daadwerkelijke betekenis. ${ }^{28}$

Ook als het gaat om gemarginaliseerde religieuze gemeenschappen in de maatschappij, is het vanuit de positieve verplichtingen die volgen uit grondrechten goed verdedigbaar als de (decentrale) overheid in het kader van positieve discriminatie een subsidie verstrekt voor de kosten van het religieuze (kerk)gebouw, om op die manier de eredienst mogelijk te maken. Overigens is de jurisprudentie met betrekking tot de positieve verplichtingen van klassieke grondrechten nog volop in beweging en is deze zeker nog niet uitgekristalliseerd. ${ }^{29}$

\subsection{Beleid inzake de leegloop van kerken binnen de context van het overheidsdomein}

Wanneer overheden (rijksoverheid, provincie, gemeente) in contact treden met kerkgemeenschappen, dienen ze zich onpartijdig op te stellen. Het gaat dan niet alleen om het daadwerkelijk onpartijdig zijn, maar ook om het voorkomen van het wekken van de schijn van partijdigheid. Als een kerkgemeenschap de indruk krijgt dat een ambtenaar (of ambtsdrager) niet onpartijdig is en andere religieuze groeperingen zal voortrekken, dan staat dit op gespannen voet met het beginsel van de scheiding tussen kerk en staat. Als ambtenaren deelnemen aan gesprekken over de toekomst van kerken, dienen zij zich daarom zoveel mogelijk zo op te stellen dat daaruit niet opgemaakt kan worden dat zij bepaalde persoonlijke voorkeuren hebben voor godsdienst in het algemeen of voor een bepaalde godsdienst in het bijzonder. Het gaat misschien wat te ver om in dit verband te eisen dat een ambtenaar zijn persoonlijke geloofs- of levensovertuiging in het geheel thuislaat (zoals bijvoorbeeld bij een rechter en een politieagent het geval is), maar hij zal zich wel altijd bewust moeten zijn van de indruk die hij wekt als hij zijn persoonlijke opvattingen te veel laat doorklinken en zo nodig zijn best moeten doen om het vertrouwen van partijen te (her)winnen.

\subsection{Beleid inzake de leegloop van kerken binnen de context van het 'particuliere' domein}

Wanneer een kerkgenootschap op eigen initiatief en geheel onafhankelijk besluit om afstand te doen van haar rechten in het kader van de godsdienstvrijheid, dan kan dat. Het beginsel van contractsvrijheid brengt met zich dat een kerkgenootschap een contract kan sluiten met een overheid waarin impliciet of expliciet afstand gedaan wordt van de rechten die uit de godsdienstvrijheid voortvloeien. Kerkgemeenschappen worden dan door de overheid behandeld als iedere andere

Kortmann (2016: 393) noemt dit als belangrijke voorwaarde voor het afleiden van positieve verplichtingen uit klassieke grondrechten.

29 Zo is er in het verleden wel een afwijzende houding geweest met betrekking tot het afleiden van positieve verplichtingen uit klassieke grondrechten. Zie ARRvS 12 maart 1987, AB 1987, 287 m.nt. Van der Vlies (Tietjerksteradeel). Het EHRM is in meer recente jurisprudentie echter veel ruimhartiger bij het afleiden van positieve verplichtingen, ook als het gaat om de godsdienstvrijheid. Zie EHRM 20 september 1994, nr. 13470/87 (Otto-Preminger-Institut v Austria), par. 56. Zie in dit verband ook de wijze waarop de Nederlandse rechter positieve verplichtingen afleidt uit artikel 2 en 8 EVRM in de Urgenda-zaak: HR 20 december 2019, ECLI:NL:HR:2019:2006. 
particuliere instelling. Anders gezegd, de overheid hoeft zich binnen het particuliere domein niet meer zo terughoudend op te stellen als binnen het interne religieuze domein. Een dergelijke gedaantewisseling van de overheid doet zich bijvoorbeeld voor bij de verkoop van een kerk aan de overheid. Als een kerk eenmaal verkocht is, mag de nieuwe eigenaar met de kerk doen wat hij wil (tenzij er sprake is van een kettingbeding waarin bepaalde voorwaarden zijn opgenomen). Dit maakt het mogelijk dat een kerk wordt omgebouwd tot discotheek of tot trampolinehal. ${ }^{30}$ Op die manier kunnen er ook tussen kerkgenootschappen en een overheid contractuele afspraken worden gemaakt over de her- of nevenbestemming van kerkgebouwen. Dit kan wellicht ook aan de orde zijn wanneer een kerkgenootschap naar aanleiding van een kerkenvisie afspraken maakt met de (decentrale) overheid, eigenaren van andere kerken, inwoners en erfgoedorganisaties.

\section{Conclusie}

Overheden kunnen bij beleidsvorming naar aanleiding van de sluiting, restauratie en de her- en nevenbestemming van kerkgebouwen worden geconfronteerd met kwesties die gevoelig liggen vanwege het beginsel van de scheiding tussen kerk en staat. Die kwesties doen zich alleen voor wanneer godsdienst een rol speelt. Belangrijk is dat overheden bedenken hoe ze zich bij deze kwesties dienen te positioneren. Het beginsel van de scheiding tussen kerk en staat schrijft voor dat de overheid zich neutraal moet opstellen. In deze bijdrage is uiteengezet dat die neutrale opstelling verschilt naar gelang het maatschappelijke domein waarbinnen het vraagstuk zich voordoet. De in deze bijdrage uitgewerkte contextuele benadering maakt duidelijk welke belangen (het religieuze, het algemene, het particuliere en het belang van anderen) juridisch gezien bij de bovengenoemde beleidsvorming doorslaggevend zouden moeten zijn binnen de verschillende domeinen.

\section{Literatuur}

Boven, T.C. van, De volkenrechtelijke bescherming van de godsdienstvrijheid, proefschrift Rijksuniversiteit Leiden, Assen: 1967.

Burg, W. van der, Het ideaal van de neutrale staat. Inclusieve, exclusieve en compenserende visies op godsdienst en cultuur, oratie Erasmus Universiteit Rotterdam, Den Haag: 2009.

Kortmann, C.A.J.M., Constitutioneel recht, Deventer: 2016.

Murdoch, J., Protecting the right to freedom of thought, conscience and religion, Council of Europe, Straatsburg: 2012.

Post, H. \& G. van der Schyff, 'De spanning tussen de margin of appreciation en de universele waarde van godsdienstvrijheid', H. Post \& G. van der Schyff, Godsdienstvrijheid in de Nederlandse rechtsorde. Nationale en Europese perspectieven, Oisterwijk: 2014, p. 79-104.

30 S. Fens, 'Een voormalige kerk omvormen tot trampolinehal? Dan is slopen toch beter', column in Trouw, 9 juni 2019. 
Jos Vleugel

Sasse van Ysselt, P. van, Financiële verhoudingen tussen overheid, kerk en religieuze organisaties, TvRRB, 2013/1, p. 65-86.

Vleugel, A., Het juridische begrip van godsdienst, proefschrift Radboud Universiteit Nijmegen, Alphen aan den Rijn: 2018.

Vleugel, A., 'Religie, belangenafweging en neutraliteit', TvRRB, 2019/3, p. 32-51.

Vleugel, A., 'Radicale moslims en religieuze tolerantie', NTM/NJCM-Bulletin, 2020/2, p. 149-170.

VNG \& BZK, Tweeluik religie in het publieke domein. Handvatten voor gemeenten over de scheiding van kerk en staat, Den Haag: 2020. 